\title{
Designing Principled Academic Discussion Tasks
}

\section{Jamie Lesley \\ Rikkyo University \\ Peter Brereton \\ Rikkyo University}

\section{Reference Data:}

Lesley, J., \& Brereton, P. (2019). Designing principled academic discussion tasks. In P. Clements, A. Krause, \& P. Bennett (Eds.), Diversity and inclusion. Tokyo: JALT.

In this paper, we introduce a principled approach to material design for academic discussion courses. This approach is informed by our experiences of creating, developing, and evaluating course materials in our roles as academic managers for a large-scale academic discussion program at a private university in Tokyo. These principles are used to assist in the writing of discussion questions conducive to academic discussion and the creation of pre-task preparation activities to support students in their discussions. We believe that the principles will be of use to teachers new to academic discussion classes as a way to guide, evaluate, and justify the design of their course materials with regard to activity aims, content, and organization. Similarly, we hope that the paper can operate as a useful review of best practice for more experienced course developers.

本論文では、アカデミックディスカッションコースの教材を作成する為の、合理的な取り組み方法を紹介する。都内のある大 学での、大規模なアカデミックディスカッションプログラムのコ一ス教材を構成、開発、および評価をした著者の経験を述べた ものである。この方式においては、まずアカデミックディスカッションを行う為の議題の作成亡、議論の際、学生に役立つ事前 準備課題のアクティビティを作成する事に重点を置いている。アカデミックディスカッションクラスの担当講師、およびコース

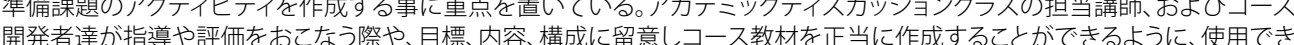
るチェックリストを紹介している。 uccessful group discussions place a large cognitive load on participants who must $\checkmark$ not only retrieve lexical items and grammatical structures to express themselves but also constantly generate, develop, and organize ideas (Robinson, 2001). It is therefore vital that students are prepared for their discussions, which can help improve fluency of ideas, build confidence, and reduce students' perceptions that their ideas are inadequate (Alexander, Argent, \& Spencer, 2008).

Taking a principled approach to academic discussion task design is important because both the creation process and the end product benefit from a rigorous examination of all components. Following a clear set of principles means materials can be more readily justified and scrutinised both before and after in-class use. This is valuable not just from an accountability perspective but also from the view of maximising learning outcomes.

In this paper, we present a series of principles to help guide, evaluate, and justify the design of academic discussion tasks in terms of their aims, content, and organization. Focus is split between discussion questions and their corresponding preparation activities. The approach taken is informed by our experiences of developing and using course materials at Rikkyo University's Center for English Discussion Class (EDC).

\section{Context}

EDC is a mandatory English course for the 4,500 to 4,700 freshman students enrolled annually at Rikkyo University. Students are streamed into one of four levels upon entry based on TOEIC scores (see Figure 1). To offer students a "genuine opportunity to develop communicative competence" (Hurling, 2012, p. 1), class size is restricted to between seven and nine students. 


\begin{tabular}{lcccc}
\hline Level & I & Il & Ill & IV \\
\hline $\begin{array}{l}\text { Combined Listening and } \\
\text { Reading TOEIC Scores }\end{array}$ & 680 or above & 480 to 679 & 280 to 479 & Below 280 \\
\hline
\end{tabular}

Figure 1. EDC levels and corresponding TOEIC scores (Center for English Discussion Class, 2018).

All EDC students discuss the same topics and develop broadly the same discussion skills throughout the course. Each skill is divided into speaker and listener skills (see Figure 2). These are first practiced through semicontrolled activities to ensure appropriate use and build automaticity, followed by two extended discussions of 10 and 16 minutes with little to no teacher intervention. Assessment is based on students' ability to use target skills as well as their strategic competencies.

\begin{tabular}{ccc}
\hline Discussion skill & Speaker skill & Listener skill \\
\hline Opinions & Giving opinions & Asking for opinions \\
& (e.g., In my opinion, ...) & (e.g., What's your opinion?) \\
Choosing topics & Choosing topics & Inviting others to choose a topic \\
& (e.g., Let's discuss...) & (e.g., What shall we discuss first?) \\
\hline
\end{tabular}

Figure 2. Discussion skill examples.

Four program managers are responsible for creating, evaluating, and revising materials. Evaluations are informed by the principles in Figures 3 and 4 as well as feedback from teachers and students. All aspects of materials development are decided collectively through discussion and trialling of potential activities. Lessons cover a range of contemporary issues, which are designed to be accessible yet challenging to 1st-year university students, encouraging discussion and critical thinking (Young, 2017). To prepare for each lesson, students read a short article in their textbook, which helps to introduce essential lexis and to seed ideas they may wish to explore in their in-class discussions. Each lesson addresses a particular topic, such as gender inequality, social media, and the aging population.

Discussions follow a 3-step structure, which begins with a preparation task designed to help students generate sufficient ideas for the subsequent discussion. Preparation is typically done as pair-work, with students then forming groups with new partners for the extended discussions. Each discussion is framed by two given questions and students must take the initiative to maintain their group interaction for the set duration. After the discussion, there is a feedback stage that is either teacher-fronted, student-led, or a combination of both.

\section{Recommendations From the Literature}

In much the same way that a principled approach to second language instruction can lead to what H. D. Brown (2007) termed "enlightened teaching" (p. 63) with improved support for students and more positive learning outcomes, it is important that theory and practice are closely connected when creating teaching materials. This is because knowing how or why something is designed a certain way enables its structure, content, and intended application to be better appraised. J. D. Brown (1995) explained that developing in-house materials should occur only after a careful consideration of curricular and syllabus requirements, course goals and objectives, and tests to determine learners' needs. As Nunan (2004) outlined, predictive-type checklists can be valid evaluations when applied to task goals and rational, input, procedures, roles and setting, implementation, grading and integration, and assessment. Once made, materials can be piloted, reviewed, and revised as necessary. Routine evaluation and modification should then follow to ensure materials remain effective and responsive to change (Bao, 2013).

In his study of task planning, Ellis (2009) distinguished between pre-task [sic] planning versus planning done during a task, or within-task. Additionally, he categorized the pre-task variety further into planning purely focused on rehearsal contrasted with strategic planning containing no rehearsive elements. For within-task types, he separated time-pressured planning subject to time limits from unpressured planning with no time limits. He also divided planning by the degree of guidance offered to students. Lastly, he classified planning by its focus on form, meaning, or a mix of both.

In EDC, preparation activities are pre-task with a priority placed on rehearsal with some strategic planning. They are also time-pressured by virtue of standard time allocations, for example 3 to 5 minutes before the first group discussion, which lasts 10 minutes, and 6 to 8 minutes before the second one, which lasts 16 minutes. As the main aim of the preparation is to create content for the discussion (Willis \& Willis, 2007), more importance is given to meaning, especially when ideas are shared with a preparation partner. However, students are always asked to keep using target skills, so a form focus is never entirely removed. 


\section{Designing Principled Discussion Activities}

In this section, we explain the principles followed when creating discussion task questions and preparation activities. Questions are dealt with first, as they should be established prior to the drafting of the preparation activity to which they are paired with in the final materials.

\section{Creating Discussion Task Questions}

The main purpose of the questions is to enable students to maintain an extended group discussion on a particular topic for a minimum duration and to allow freer practice of target skills. Important factors to consider are outlined in Figure 3.

\section{Principle}

1. Questions should generate sufficient ideas to develop a given topic for a given duration.

2. Questions should produce a variety of responses to guarantee a genuine need to discuss.

3. Questions should allow for repeated practice of target skills.

4. Questions should allow for use of a variety of previously taught skills.

\section{Details}

It is neither desirable nor necessary for students to wander into unrelated topics simply to "fill time".

Questions that elicit preferences or experiences are not conducive to academic discussion as they lead more naturally to conversations and anecdote sharing. Instead, questions should develop topics through the analysis and negotiation of ideas and opinions.

Questions should promote use of target skills, but question wording should not include a target skill itself. If the aim is to practice giving and asking for reasons, a question like "Why is it a good idea to...?" is misplaced. Further, if the discussion skill is organizational, questions should provide multiple opportunities for this, for example, through bullet-pointed prompts.

Skills learned in previous lessons should be considered to allow regular revision throughout the course. \begin{tabular}{c} 
Principle \\
\hline $5 . \quad$ Language should be accurately
\end{tabular} graded to the students' level.

6. Students should be able to discuss the questions with pre-existing knowledge and vocabulary.

7. The preparation task focus and first discussion question should be linked to enable meaningful repetition of skills and content.

8. The link between the thematic focus of the first and second questions should be explicit.

\section{Details}

Questions must be comprehensible to students using their existing language. Unfavourable wordings typically include overly prosaic or technical phrasing.

Question topics should be academic, but not entirely unfamiliar to students, to promote critical thinking about the issues raised. To support this aim, essential lexis should be introduced in texts and preparation activities.

Task repetition, whereby students repeat the same or slight variations of their ideas, eases cognitive load and improves task performance.

Questions should be clearly linked to the lesson topic and to one other, but scope also exists for the second question to move away from the initial focus of the first question.

Figure 3. Design principles for discussion task questions.

\section{Designing Preparation Activities}

As the rationale for designing preparation activities is in part very similar to that of writing discussion questions, Principles 3-5 in Figure 4 are outlined in brief to avoid repetition. 


\section{Principle}

1. The activity should allow students to generate on-topic ideas.

2. The activity should allow for a variety of responses to guarantee a genuine need to communicate.

3. The activity should allow for repeated practice of target skills.

4. The activity should allow for use of See Principle 4 in the Discussion Questions a variety of previously taught skills.

5. Language should be accurately graded to the students' level.

6. Students should be able to discuss See Principle 6 in the Discussion Questions the content with pre-existing knowledge and vocabulary.

7. Activity complexity should be sufficiently low to ensure students can focus on content.

\section{Details} for the subsequent discussion.

Although the main aim of the activity is content generation, the preparation activity the target skill.

checklist.

See Principle 5 in the Discussion Questions checklist. checklist.

Given the main aims of the preparation to
The main aim of any preparation activity is to enable students to generate and develop ideas

If all students have the same ideas, there is little communicative reason for them to be shared. should also provide scope for freer practice of facilitate idea development and practice target skills, cognitive load should not be increased through unnecessary complexity.

Figure 4. Design principles for discussion preparation activities.

\section{Examples in Use}

To show how the principles lead to created materials, we will now detail common preparation activity types and discussion questions in the 2018-2019 EDC textbook (Brereton, Lesley, Schaefer, \& Young, 2018a, 2018b). The first example is explained with reference to the individual principles that informed its design. The other examples are covered in brief with specific highlights of their design features and appear in full in the Appendix. In all cases, tasks and questions were designed in accordance with the principles outlined in this paper: for example, preparation items were chosen on the basis of familiarity, relevance, and scope for response variety; concepts and language were kept simple to steer students towards content generation and continued use of target skills; each pair of discussion questions was clearly related to its assigned preparation activity and the two individual questions were thematically linked to each other. Overall, immediate accessibility and an ability to use target skills with all preparation activity and question content were always prioritised.

The first example is Check Marks in One Column, a simple preparation activity approach where students select items from a set of fixed choices in consideration of a single given factor, target, or topic (see Figure 5). In this instance, the topic is social pressures felt by most university students, which is expected to be familiar and accessible to all students.

Preparation Activity: Below are six pressures from society. Which pressures do most university students feel? Put check marks $(\checkmark)$ in the boxes below. Discuss your ideas with a partner.

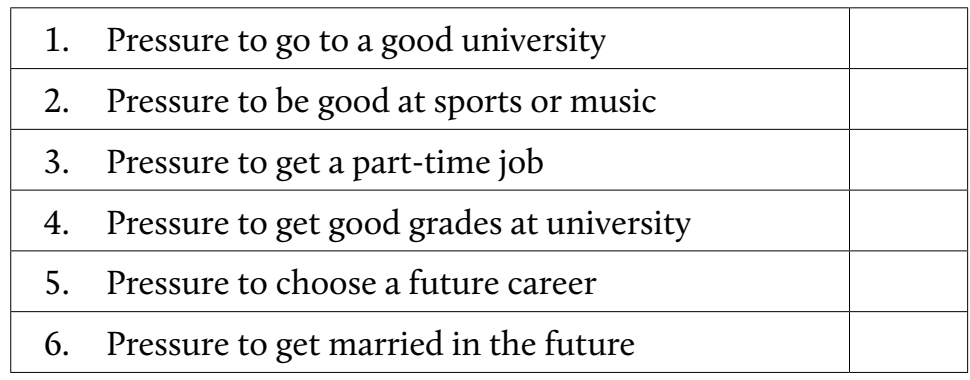

\section{Group Discussion Questions:}

1. Do university students feel pressure from society?

2. Is pressure from society good or bad?

Figure 5. Check marks in one column.

All preparation items should help students generate on-topic ideas for a subsequent, related discussion (Principle 1) and the six items in Figure 5 were included on that basis with a clear connection to the two group discussion questions. In theory, it is possible that all students will select (or not select) exactly the same items from the preparation input, but variety in their responses is the more likely scenario. This should allow for a 
genuine need to communicate during the pair-work stage of the preparation (Principle 2 ), when students ask each other what they think about each type of pressure. Individual motivations for selecting certain items may also differ from one person to the next, which again provides scope for different responses to be generated.

Enabling students to gain repeated practice of target skills (Principle 3) is another important factor in the design of the preparation materials. This specific activity comes from a lesson in which the examples skill (asking for / giving) and joining a discussion skill (inviting others to take the floor / requesting to take the floor yourself) are reviewed ahead of a formal discussion test. During the pair-work interaction of the preparation, students should be able to use these skills multiple times in both the speaker and listener role. Successful design will therefore facilitate continued practice of skills for content generation (examples) and for organisation (joining a discussion). Concurrently, the activity should provide scope for a variety of previously learned skills to feature (Principle 4). In this instance, those skills are opinions (asking for / giving) and reasons (asking for / giving), that is, students also need to exchange and justify their beliefs about the given types of social pressure.

The language used in the preparation activity is graded to be understandable and accessible (Principle 5), that is, pitched at a level that avoids overly prosaic or technical words. All preparation content and concepts should be able to be discussed with students' pre-existing knowledge and lexis (Principle 6) and should consequently be low in complexity (Principle 7). With this particular task, ideas related to entering a good university, getting good grades, being good at certain activities, and getting a parttime job are all fairly standard considerations for university students. Similarly, group members may not have decided on their own career paths yet, but they should be aware of the need for one to be chosen at some point. Equally, marriage should be a concept known to all.

Moving on to the principles behind the design of the group discussion questions, both are about social pressure and geared towards developing ideas around this topic for a set duration (Principle 1). The first question links directly to the focus of the preparation activity (i.e., university students and social pressure), whereas the second question is broader and allows the discussion to move towards a consideration of other age groups or communities. Both questions, however, clearly relate to the overall topic, as well as to each other (Principle 8) and should provide enough content that students do not need to diverge from the discussion topic to fill time.

Both discussion questions are intended to generate a variety of responses (Principle 2), which should be possible for several reasons. First, the group discussion always follows the preparation activity, which itself is designed to elicit a range of responses. Before group members discuss anything, they are encouraged to repeat their ideas from the preparation. The first of the two set questions allows for this repetition because of its crossover in focus with the preparation content (Principle 7). The variety of ideas first exchanged in the preparatory pair-work should therefore carry over to the group interaction. Even if students' initial answers are the same, that is, everyone agrees that university students do indeed feel pressure from society, their respective reasons should be individually motivated and thus uniquely positioned to develop the topic as the discussion progresses. It is here that the questions' scope for target skills (Principle 3) and previously taught skills (Principle 4) to be used repeatedly comes into play.

As with the preparation activity, the language and concepts of the discussion questions are again kept deliberately simple (Principles 5 and 6 ). In the case of Figure 5, both questions are closed and generate a straightforward yes/no answer binary. Target skills, such as giving reasons or asking for examples, can be used in this simple platform to then explore people's opinions in greater detail. In addition, because the audience is different from the preparation activity, the need to communicate ideas in the group format remains genuine and meaningful. In this way, all design principles for the creation of the group discussion questions and the preparation activity are realised. What follows is a brief overview of some alternatives to the preparation activity design from Figure 5 (see Appendix for all activities).

\section{Variations}

The first alternative is Check Marks in Two Columns (Appendix A), which shows how complexity can be added to the type used in Figure 5 with two factors, targets, or topics to consider. In this example, students make selections based on gender pressures felt by men and women. The Check Marks in a Table (Appendix B) activity takes a similar approach but offers multiple options for multiple factors. This suits more challenging topics, like this petty crime example. Providing an optional "other" category also affords additional flexibility to move beyond the provided input.

The Binary Choice preparation activity (Appendix C) uses a table approach except that different options are provided in each column to allow for a large number of items to be covered. This suits topics for which content generation might be challenging. In the Binary Choice with Multiple Categories version (Appendix D), the preparation activity presents a simple binary to apply to a list of items. In the example, the topic and items are all money-related and expected to be familiar to students. 
The Multiple Choice design type (Appendix E) shows how complexity can be added to the preparation activity by categorising aspects of the topic into subtopics. The example topic of how to reduce poverty presents four categories each with two solutions against which the binary choice is applied.

The Ranking preparation activity (Appendix F) suits discussions in which students decide the best/worst or most/least of something. In the example, five risks of social media are ranked from most to least serious. Ranking items facilitates an eventual discussion about what the most serious risks are.

The Choose Three preparation activity (Appendix G) requires students to discriminate the most/least out of typically six to eight items with the aim of achieving response variety. In the example, students consider how to reduce gender inequality with eight items spanning four spheres of influence.

The Stations preparation activity (Appendix $\mathrm{H}$ ) takes its name from the manner in which it is typically set up in class. Usually, teachers take this activity out of the textbook by photocopying each of the four items and placing them at different points around the classroom. Pairs can then circulate around the room, stopping at each "station" to discuss its content. In the example, a binary choice is attached to each of four solutions to Japan's aging population problem. The Stations With Opinions on One Topic activity (Appendix I) is a variation of the stations approach in which the prompts appear as opinions from characters. This allows for more detailed information to be conveyed and is useful for more abstract or unfamiliar topics. In the example, students are asked to respond to four opinions about punishing serious crimes, including the death penalty-a topic that mos 1st-year university students in Japan will never have discussed in English before. The Stations With Opinions on Multiple Topics activity (Appendix J) shows a further variation on the stations formula. The difference is that unique topics are covered by each character's opinion, allowing for more subtopics to be covered. In the example, students are asked to agree or disagree with four beliefs about new media. These subtopics appear in bullet point form in the group discussion questions below.

This list is not intended to be exhaustive but covers the most common preparation activity types used in the EDP context. Certainly, other types exist, and variations can of course be made to the examples presented. Indeed, it is perhaps inevitable, as Bao (2013) explained, that materials can be and frequently are reinterpreted in ways that were not part of their creators' original intent. Modifications are an integral part of how materials become positively re-envisaged to keep them fresh and effective as teachers strive to improve previous designs and applications. For every EDC preparation activity type described, complexity can be increased by introducing more items to consider or giving less time to consider them. Conversely, removing items or extending time can simplify matters. However, these changes are not without consequence for the eventual group discussions. If a preparation activity is limited by time or content, for example, it places a greater burden on group members to then generate sufficient on-topic content middiscussion. This can unhelpfully increase cognitive load and may coincide with a drop in target skills use if attentional resources become stretched (Skehan, 1998). For relatively familiar topics, online planning and idea generation is not typically problematic for its effect on target skills, but it can be for more challenging ones. Hence, additional content in the preparation is usually provided for less accessible or unfamiliar topics so that target skills do not get marginalised in the group discussion that follows.

\section{Conclusion}

While not offered as an exact blueprint, we hope that the design principles outlined in this paper will be useful in helping others create effective class materials for their own teaching contexts. In a world of ever-increasing, globally oriented commercial materials made for an amorphous mass market, the need for quality homemade materials that can more appropriately meet local needs has arguably never been greater (Bao, 2013). Equally, the need for a principled approach to how those homemade materials are made has never been more relevant to the discussion than it is now.

\section{Bio Data}

Jamie Lesley is a program manager at Rikkyo University's Center for English Discussion Class. He taught in the U.K. and U.S.A. before moving to Japan in 2003, where he continues to gain experience in HR management and teacher training, EAP and ESP instruction, materials development, and formalized language testing. His current interests include testing and assessment, intercultural communication, and professional development in second-language teacher education. <jslesley2001@yahoo.co.uk>

Peter Brereton is a program manager at Rikkyo University's Center for English Discussion Class and is also a Delta Local Tutor and External Assessor. He has worked in Japan since 2012 and previously worked in Spain, Germany, France, Latvia, Australia, Ireland, and the U.K. He holds a Delta and an MA in TESOL, and his current interests include teacher creativity, feedback methods, teacher professional development, and reflective practice. <brereton.peter@gmail.com> 


\section{References}

Alexander, O., Argent, S., \& Spencer, J. (2008). EAP essentials: A teacher's guide to principles and practice. Reading, England: Garnet Education.

Bao, D. (2013). Developing materials for speaking skills. In B. Tomlinson (Ed.), Developing materials for language teaching (pp. 407-428). London, England: Bloomsbury Academic.

Brereton, P., Lesley, J., Schaefer, M. Y., \& Young, D. (2018a). What do you think? Interactive skills for effective discussions 1. Tokyo: DTP Shuppan.

Brereton, P., Lesley, J., Schaefer, M. Y., \& Young, D. (2018b). What do you think? Interactive skills for effective discussions 2. Tokyo: DTP Shuppan.

Brown, H. D. (2007). Teaching by principles: An interactive approach to language pedagogy. New York. NY: Pearson Education.

Brown, J. D. (1995). The elements of language curriculum: A systematic approach to program development. Boston, MA: Cengage Learning.

Center for English Discussion Class. (2018). Instructor handbook (Unpublished internal document). Rikkyo University.

Ellis, R. (2009). The differential effects of three types of task planning on the fluency, complexity, and accuracy in L2 oral production. Applied Linguistics, 30(4), 474-509. https://doi.org/10.1093/ applin/amp042

Hurling, S. (2012). Introduction to EDC. New Directions in Teaching and Learning English Discussion, 1(1), 1.2-1.10

Nunan, D. (2004). Task-based language teaching. Cambridge, England: Cambridge University Press. Skehan, P (1998). A cognitive approach to language learning. Oxford, England: Oxford University Press.

Robinson, P. (2001). Task complexity, task difficulty, and task production: Exploring interactions in a componential framework. Applied Linguistics, 22(1), 27-57. https://doi.org/10.1093/ applin/22.1.27

Willis, D., \& Willis, J. (2007). Doing task-based teaching. Oxford, England: Oxford University Press. Young, D. (2017). Textbook revision in the EDC context: Lesson activities. New Directions in Teaching and Learning English Discussion, 5, 313-319.

\section{Appendix A}

Check Marks in Two Columns

Preparation Activity: Below are six examples of pressure. Which types of pressure do men and women feel? Put check marks $(\checkmark)$ in the boxes below. Discuss your ideas with a partner.

\begin{tabular}{|c|l|l|l|}
\hline \multicolumn{2}{|c|}{ Pressure } & Men & Women \\
\hline 1. & To earn a lot of money & & \\
\hline 2. & To get married & & \\
\hline 3. & To have children & & \\
\hline 4. & To be fashionable & & \\
\hline 5. & To be polite & & \\
\hline 6. & To be good at sports & & \\
\hline
\end{tabular}

\section{Group Discussion Questions:}

1. Do men and women have the same types of pressure?

2. What are the most serious types of gender pressure? 


\section{Appendix B}

\section{Check Marks in a Table}

Preparation Activity: Below are some petty crimes and possible punishments. What is the best punishment for each crime? Put check marks $(\checkmark)$ in the boxes. Discuss your ideas with a partner.

\begin{tabular}{|c|c|c|c|c|}
\cline { 2 - 5 } \multicolumn{1}{c|}{} & Prison & A fine & A warning & Other? \\
\hline Shoplifting & & & & \\
\hline Driving Dangerously & & & & \\
\hline Graffiti & & & & \\
\hline Telephone scams & & & & \\
\hline
\end{tabular}

\section{Group Discussion Questions:}

1. What is the best punishment for petty crimes? Discuss:
- Shoplifting
- Driving dangerously
- Graffiti
- Telephone scams

2. Should criminals always be punished?

\section{Appendix C \\ Binary Choice}

Preparation Activity: Below are eight things that students can do with their money. For each thing, decide if it is good or bad. Discuss your ideas with a partner.

1. Saving for an emergency

(good/bad)

2. Saving for something special (e.g. a wedding, a house)

$($ good / bad $)$

3. Donating to charity

(good/bad)

4. Buying things for yourself (e.g., clothes, video games)

(good/bad)

5. Buying gifts for your friends and family

(good/bad)

6. Travelling abroad

$($ good / bad $)$

7. Eating expensive food

(good/bad)

8. Starting a business

$($ good / bad $)$

\section{Group Discussion Questions:}

1. What are some good things for students to do with their money?

2. What should students not do with their money? 


\section{Appendix D}

Binary Choice With Multiple Categories

Preparation Activity: Below are some ideas about how to reduce poverty. For each idea, decide if it is good or bad. Discuss your ideas with a partner.

\begin{tabular}{|c|l|c|}
\hline \multirow{2}{*}{$\begin{array}{c}\text { Social } \\
\text { services }\end{array}$} & Providing free childcare for poor families & $\mathrm{good} / \mathrm{bad}$ \\
\cline { 2 - 3 } & Providing free health services for poor people & $\mathrm{good} / \mathrm{bad}$ \\
\hline \multirow{2}{*}{ Taxes } & Raising taxes for rich people & $\mathrm{good} / \mathrm{bad}$ \\
\cline { 2 - 3 } & Lowering taxes for poor people & $\mathrm{good} / \mathrm{bad}$ \\
\hline \multirow{2}{*}{ Work } & Raising the minimum wage & $\mathrm{good} / \mathrm{bad}$ \\
\cline { 2 - 3 } & Helping poor people find good jobs & $\mathrm{good} / \mathrm{bad}$ \\
\hline \multirow{2}{*}{ Charity } & Volunteering & $\mathrm{good} / \mathrm{bad}$ \\
\cline { 2 - 3 } & Donating money and goods $/ \mathrm{bad}$ \\
\hline
\end{tabular}

\section{Group Discussion Questions:}

1. What are good ways to reduce poverty? Discuss:

- Social services - Taxes

- Work

- Charity

\section{Appendix E}

Multiple Choice

Preparation Activity: Below are four choices about how to have a good study abroad experience. For each choice, decide what students should do. Discuss your ideas with a partner.

\begin{tabular}{|c|c|c|c|}
\hline How long to stay & one month & three months & one year \\
\hline Where to live & in a big city & in a small town & in the countryside \\
\hline Who to live with & alone & other students & a host family \\
\hline $\begin{array}{c}\text { Who to be friends } \\
\text { with }\end{array}$ & $\begin{array}{c}\text { mostly Japanese } \\
\text { students }\end{array}$ & $\begin{array}{c}\text { mostly } \\
\text { international } \\
\text { students }\end{array}$ & $\begin{array}{c}\text { mostly local } \\
\text { people }\end{array}$ \\
\hline
\end{tabular}

\section{Group Discussion Questions:}

1. What should students do to have a good study abroad experience? Discuss:

- How long to - Where to live - Who to live with - Who to be stay friends with

2. Is it possible to end poverty?

2. Is studying abroad a good way to learn a foreign language? 


\section{Appendix $\mathrm{F}$ \\ Ranking}

Preparation Activity: What are the most serious risks of social media? Rank the following risks from 1 (the most serious risk) to 5 (the least serious risks). Discuss your ideas with a partner.

\begin{tabular}{|l|l|}
\hline \multicolumn{1}{|c|}{ Risks } & Ranking \\
\hline Personal privacy & \\
\hline Physical health & \\
\hline Mental health & \\
\hline Fake news & \\
\hline Online bullying & \\
\hline
\end{tabular}

\section{Group Discussion Questions:}

1. What are the most serious risks of social media?

2. Is social media good or bad for society?

\section{Appendix G}

\section{Choose Three}

Preparation Activity: Below are eight ideas about how to reduce gender inequality. What ideas would be most effective? (Choose three.) Discuss your ideas with a partner.

_-_ Voters electing more female politicians (e.g., mayor, Diet member)

_-_ Companies supporting working mothers

_-_ Companies paying men and women the same salary for the same job

___ Companies hiring more female managers in companies

___ Men doing more housework (e.g. cooking, cleaning)

_-_ Men spending more time taking care of children

___ Parents teaching children to respect different genders

___ Media reducing gender stereotypes

\section{Group Discussion Questions:}

1. What are some good ways to reduce gender inequality?

2. Should the government do more to reduce gender inequality? 


\section{Appendix $\mathrm{H}$ \\ Stations}

Preparation Activity: Below are four solutions to the aging population problem. For each solution, decide if it is good or bad. Discuss your ideas with a partner.

\section{Increasing immigration:}

- More foreign people will live and work in Japan.

$(\operatorname{good} / \mathrm{bad})$

\section{Using healthcare robots:}

- Robots will help elderly people with housework, shopping, etc. (good/bad)

\section{Having more children:}

- Families in Japan will have more children.

$($ good / bad $)$

\section{Raising the retirement age:}

- People will work until they are 70 years old.

$(\operatorname{good} / \mathrm{bad})$

\section{Group Discussion Questions:}

1. What are some good solutions to the aging population? Discuss:
- Increasing
- Using healthcare
- Having more
- Raising the immigration
robots children
retirement age

\section{Appendix I}

Stations With Opinions on One Topic

Preparation Activity: Below are four opinions about punishing serious crimes. For each opinion, decide if you agree or disagree. Discuss your ideas with a partner.

Eri: I think the death penalty should only be used for really serious crimes, for example, murder or terrorism. This will make ordinary people feel safer. (agree / disagree)

Jun: In my opinion, all criminals deserve a second chance. Even bank robbers and dangerous gang members can change after a long time in prison. (agree / disagree)

Aki: I don't think the government should kill anyone. The death penalty is wrong. Violent criminals should be punished with life in prison. (agree / disagree)

Ryo: I think the death penalty should never be used because innocent people are sometimes given the death penalty by mistake. It's too risky. (agree / disagree)

\section{Group Discussion Questions:}

1. What is the best way to punish serious crimes?

2. Is it important to help criminals return to society? 


\section{Appendix J}

Stations With Opinions on Multiple Topics

Preparation Activity: Below are four opinions about new media. For each opinion, decide if you agree or disagree. Discuss your ideas with a partner.

Eri: I think social media is great. I can let my friends know what l'm doing, and they can reply quickly. I can stay in touch with everyone all day! (agree / disagree)

Jun: I think universities should offer online classes. When I was a high school student, my cram school had online classes, so I could easily study at home.

(agree/disagree)

Aki: In my opinion, using library books is better than using websites to get information. For example, Wikipedia has lots of wrong information! (agree / disagree)

Ryo: I think people spend too much time online. Many of my friends watch YouTube for hours and hours every day! It's so unhealthy and a waste of time.

(agree / disagree)

\section{Group Discussion Questions:}

1. Do these types of new media make people's lives better?

- Social media - Online classes - Websites - YouTube

2. What is the most useful form of new media? 